\title{
Empirical Findings from an Ascending Stair Evacuation Exercise in a Subway Station
}

\author{
Helmut Schrom-Feiertag', Thomas Matyus ${ }^{1}$, Martin Stubenschrott ${ }^{1}$, Stefan Seer ${ }^{1}$ \\ ${ }^{1}$ Center for Mobility Systems, AIT Austrian Institute of Technology GmbH \\ Giefinggasse 2, 1210 Vienna, Austria \\ \{Helmut.Schrom-Feiertag, Thomas.Matyus, Martin.Stubenschrott, Stefan.Seer\}@ait.ac.at
}

\begin{abstract}
Crowd simulations have proven to be a valuable numerical tool for evacuation analysis. There is series of research and empirical evacuation studies for infrastructures and buildings. In contrast to research on evacuation via descending stairs, little attention has been given to ascending stairs, but they are an important criterion, especially in subway stations with high passenger frequencies. In this paper, we present the findings from an evacuation exercise in a subway station with long ascending stairs. The empirical findings showed an increasing walking time on the ascending stairs during evacuation. Also, the flow rate differs with higher flow rates at the beginning of the stairs and lower values at the end of the stairs. The mechanism behind these results has still to be investigated, but the findings already provide an interesting basis for modelling and validating evacuation simulations over long ascending stairs.
\end{abstract}

Keywords: pedestrian, emergency evacuation, subway station, ascending stair, empirical study

\section{Introduction}

Crowd simulations have proven to be a valuable numerical tool for the investigation of the evacuation performance for different infrastructures and buildings in the case of an emergency [1], [2]. Such crowd simulation models can only fully exploit their potential if they are based on an empirical basis [3]. Due to its unforeseeable occurrence, data from real emergency evacuations is hard to collect. Thus, evacuation experiments, either announced or unannounced, with scripted scenarios have been conducted and their results published in literature [4]-[10]. The focus of these evacuation experiments ranges from particular infrastructure elements, e.g. staircases [5]-[7], to route-choice behaviour [8] and walking behaviour at bottlenecks [9]. In the view of subway stations with long ascending stairs, the publication of [10] is to be emphasized here. In [10] the challenges of long ascending stairs are considered and a comprehensive literature review was carried out. They found that the influence of physical exhaustion on walking speed on long staircases and escalators had already been investigated in previous studies, but it was neither determined when physical exhaustion begins to affect walking speed nor to what extent. In addition, mainly young and healthy persons were involved in experiments, which must also be considered when utilizing the results. For a better understanding it is therefore necessary to carry out further investigations.

\section{Evacuation Scenarios}

The emergency evacuation exercise was carried out at a subway station in Vienna in December 2017. The station was chosen for two reasons, 1) it is closely located to a soccer stadium and hence used by large numbers of passengers at events, and 2) it is one of the deepest stations with a height difference of 23.2 meters below ground level. The station is equipped with a staircase with a width of 2.4 meters at both ends and an additional escalator with three lanes on one side.

The scenarios for the emergency evacuation exercise were designed to represent a peak occupancy as it can occur during the morning peak or in the context of nearby events (e.g. soccer game). Furthermore, the occurrence of technical limitations in the station building, e.g. due to regulations or because of maintenance work, was considered and only one escalator lane was available but switched of and stood still. The 
elevators were also not available for evacuation, as they are reserved for the rescue services in the event of an emergency. Another simplification for the evacuation scenario was that all participants in the front half of the platform left the station via the front exit over the ascending staircase or ascending escalator and the participants in the rear half to the rear exit with only one staircase.

The exercise was executed in two scenarios with 560 participants each. In the first scenario the front half of the train and in the second scenario only the rear half of the train was filled with the full capacity of 420 persons and in addition 140 persons waited according to the scenario on the front or rear half on the platform. Immediately after the train had arrived and the doors were open the participants started to evacuate. The evacuation exercise was recorded with video cameras for analysis. Video screenshots taken at the platform, at the staircase and on the escalator, are shown in Fig. 1.
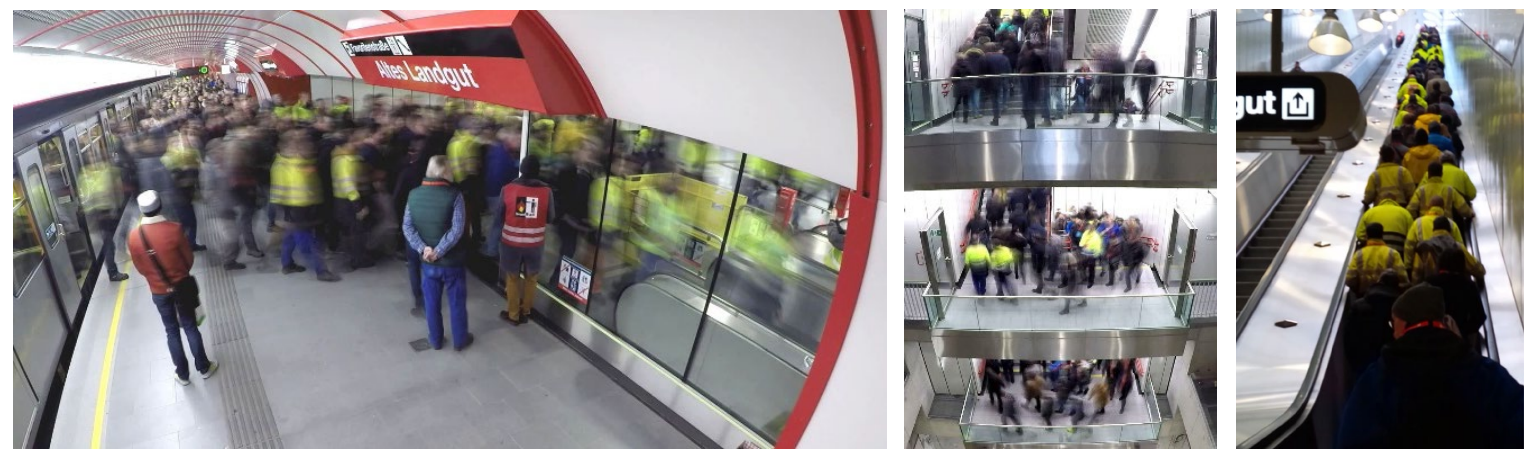

Fig. 1: Video screenshots showing people (left) leaving the train over the platform to the front escalator and staircase, (centre) on the staircase and (right) on the long ascending escalator.

\section{Results}

The time for evacuation, walking times, pedestrian flow rates and densities for both staircases and the escalator were manually extracted from the recorded video footage. Fig. 2shows the results for scenario 2 with a single ascending staircase to illustrate the empirical findings. In Fig. 2a, the decreasing number of persons inside the station over the evacuation duration can be seen. The orange line shows the number of people still on the platform at the lower level and the blue line shows the number of people still in the station and decreases over time until everyone has left the station. At time 273 seconds or 57 percent of the total duration the platform level is cleared ( $\left.\mathrm{t}_{\text {platform }}\right)$ and all persons are either on the staircase or have already left the station. After the total evacuation time of 483 seconds $\left(t_{\text {station }}\right)$ everyone has left the station through the exit on the surface. At first glance, the orange and blue lines appear parallel, but the evaluation of the walking times based on the difference between these two lines along the $\mathrm{x}$-axis shows that the blue line has a flatter course.

Fig. $2 \mathrm{~b}$ shows the walking times and walking speeds on the staircase. For each participant the time entering the staircase (x-value) and the duration on the stairs (y-value) is shown. The continuous increase in walking time from 112 seconds to 220 seconds over the duration of the evacuation should be emphasized here. The average walking time is 189 seconds. The total length of the path over the stairs was 112 meters and was divided into 10 stair segments with in total 156 steps and 57 meters length connected by 9 stair landings with total length 48 meters and a final 7 meters stretch towards the exit. Overall, a level difference of 23.2 meters was overcome. The calculated speeds are in a range of 0.5 to $1.1 \mathrm{~m} / \mathrm{s}$. The average walking speed with $0.6 \mathrm{~m} / \mathrm{s}$ is within the range of the studied literature in [10] ranging from 0.27 to $0.75 \mathrm{~m} / \mathrm{s}$.

In Fig. $2 \mathrm{c}$ the pedestrian flow measured at the beginning of the stairs and at the exit is shown. For better visual representation the values are smoothed using a sliding window with a 15 seconds interval. The beginning of the staircase represents a bottleneck where the flow rate initially increases rapidly to a maximum value of 1.16 Persons per meter per second $(\mathrm{P} / \mathrm{ms})$ and then fluctuates around the average of 0.86 $\mathrm{P} / \mathrm{ms}$. The flow rate at the exit rises slowly until it reaches the range around the average of $0.57 \mathrm{P} / \mathrm{ms}$ and oscillates around that value. The flow at the exit was clearly smaller than at the beginning of the stairs. Just in front of the stairs, the crowd density was in average $2.5 \mathrm{Persons} / \mathrm{m}^{2}$ without strong variations. 


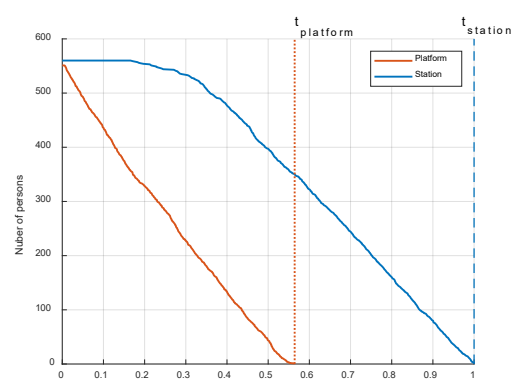

(a)

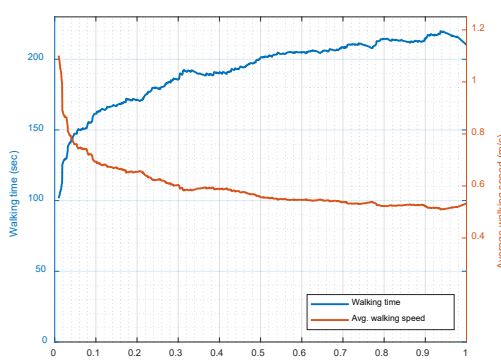

(b)

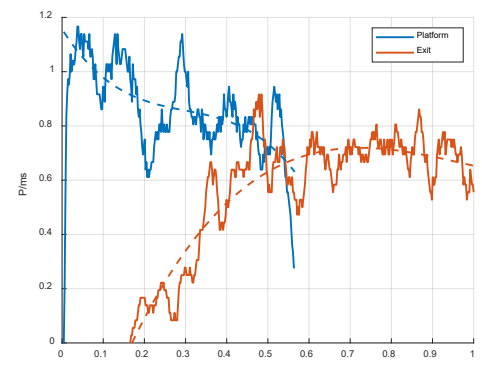

(c)

Fig. 2: Course of (a) number of persons on platform (orange line) and inside station during evacuation (blue line), (b) walking times (blue) and walking speeds (orange) from entering the stairs until leaving the building and (c) flow rates at the beginning (blue) and at end of stairs (orange).

\section{Conclusion}

The empirical findings showed that after 483 seconds the station was evacuated over long ascending stairs, whereby a distance of 174 meters and a level difference of 23.2 meters was overcome. While the average walking time was 189 seconds and the average walking speed $0.6 \mathrm{~m} / \mathrm{s}$, a steady increase of walking time from 112 to 220 seconds and decrease of walking speed from 1.1 to $0.5 \mathrm{~m} / \mathrm{s}$ on the ascending stairs was observed. Also, the flow rate differs with higher flow rates at the begin of the stairs, in average $0.86 \mathrm{P} / \mathrm{ms}$ and lower values at end of the stairs with an average of $0.57 \mathrm{P} / \mathrm{ms}$. It seems that after congesting at the begin of the stairs the people start to keep a greater distance from each other and the crowd spreads out along the stairs. The mechanism behind these results and how strong physical exhaustion plays a role has still to be investigated, but the findings already provide an interesting basis for modelling and validating evacuation simulations over long ascending stairs.

\section{References}

[1] S. Gwynne, E. Kuligowski, and D. Nilsson, "Representing evacuation behavior in engineering terms," J. Fire Prot. Eng., vol. 22, no. 2, pp. 133-150, May 2012.

[2] D. C. Duives, W. Daamen, and S. P. Hoogendoorn, "State-of-the-art crowd motion simulation models," Transp. Res. Part C Emerg. Technol., vol. 37, pp. 193-209, 2013.

[3] A. Schadschneider, W. Klingsch, H. Klüpfel, T. Kretz, C. Rogsch, and A. Seyfried, "Evacuation Dynamics: Empirical Results, Modeling and Applications," in Encyclopedia of Complexity and Systems Science, R. A. M. Ph. D, Ed. Springer New York, 2009, pp. 3142-3176.

[4] M. L. Isenhour and R. Löhner, "Validation of a Pedestrian Simulation Tool Using the NIST Stairwell Evacuation Data," Transp. Res. Procedia, vol. 2, pp. 739-744, Jan. 2014.

[5] S. Burghardt, A. Seyfried, and W. Klingsch, "Performance of stairs - Fundamental diagram and topographical measurements," Transp. Res. Part C Emerg. Technol., vol. 37, pp. 268-278, 2013.

[6] R. D. Peacock, "Building Occupant Evacuation," NIST, 25-May-2010. [Online]. Available: https://www.nist.gov/el/fire-research-division-73300/building-occupant-evacuation. [Accessed: 08-Feb-2018].

[7] E. Ronchi, P. A. Reneke, E. D. Kuligowski, and R. D. Peacock, "An analysis of evacuation travel paths on stair landings by means of conditional probabilities," Fire Saf. J., vol. 65, pp. 30-40, 2014.

[8] M. Stubenschrott, T. Matyus, H. Schrom-Feiertag, C. Kogler, and S. Seer, "Route-Choice Modeling for Pedestrian Evacuation based on Infrastructure Knowledge and Personal Preferences," presented at the Transportation Research Board 96th Annual Meeting, Washington, DC, 2017.

[9] S. Hoogendoorn, W. Daamen, and P. Bovy, "Extracting Microscopic Pedestrian Characteristics from Video Data," in TRB 2004 Annual Meeting, 2004.

[10] J. Norén, M. Delin, and K. Fridolf, “Ascending Stair Evacuation: What do We Know?," Transp. Res. Procedia, vol. 2, pp. 774-782, Jan. 2014. 